\title{
La comunidad de San Sebastián a fines del siglo XV: un movimiento fiscalizador del poder concejil
}

\author{
ERnesto García Fernández*
}

\section{INTRODUCCIÓN}

La villa de San Sebastián, fundada en 1180 por el rey navarro, Sancho VI, fue modelando su sistema de organización concejil desde la propia concesión de su carta foral. De manera particular se señala en ésta que al final de cada año los pobladores de la villa elegirán al alcalde y al preboste. Asimismo se especifica que los alcaldes se ocuparían de juzgar los pleitos existentes entre los vecinos.

Pero a fines del XII la jurisdicción territorial de San Sebastián se extendía por zonas mucho más amplias, incluyendo una serie de localidades, que a lo largo de los siglos XIII al XV se desarrollarán hasta el punto de desgajarse de aquélla y de constituirse algunas de ellas en villas, otras se incorporarán a las villas más próximas. Desde este punto de vista, podría afirmarse que San Sebastián pierde el primitivo protagonismo político en la comarca, adquirido a fines del XII, durante la baja Edad Media. Esta circunstancia significará una mienor producción de bienes agrarios en sus términos y por lo tanto una mayor dependencia del exterior en lo que se refiere al abastecimiento de sus vecinos, si bien las exenciones a sus naves y mercaderes desde el año 1180 evidencian desde un primer momento las pretensiones de una proyección internacional de la villa ${ }^{1}$.

* Titular de Ha. Medieval. Universidad del País Vasco (Vitoria).

Orella, J. L., "Estudio jurídico comparativo de los Fueros de San Sebastián, Estella, Vitoria y Logroño», El Fuero de San Sebastián y su época. San Sebastián 1982; SerRano, L., «San Sebastián y Fuenterrabía, dos puertos claves en las importaciones castellanas del Xill", El Fuero de San Sebastián y su época. San Sebastián 1982; ARIZAGA, B., El nacimiento de las villas guipuzcoanas en los siglos XIII y XIV. Morfología y funciones urbanas. San Sebastián 1978. 
Por lo tanto, San Sebastián se proyecta hacia el mar, no en vano la documentación presenta a numerosos mercaderes y transportistas, vecinos de la villa, recorriendo los puertos marítimos del Océano Atlántico y del Mar Mediterráneo durante los siglos XV y XVI. Es precisamente en estos siglos cuando esta villa, a pesar de los conflictos fronterizos con las tropas del rey de Francia en la segunda mitad del siglo xv y de algunas limitaciones para el normal desarrollo del comercio o la quema parcial de la villa en el incendio que sufrió en 1489, aparece ante nuestra vista como plena de euforia y dinamismo. Esta imagen, no lo olvidemos, es consecuencia de la existencia de una documentación mucho más abundante para estas centurias ${ }^{2}$.

Esta señalada pujanza de San Sebastián generó, sin embargo, numerosos conflictos en el terreno de las instituciones municipales en los años finales del siglo $x \mathrm{~V}$. El objetivo, sin embargo, de este artículo se va a circunscribir fundamentalmente al estudio de las relaciones entre las oficiales de la villa y la "Comunidad» de San Sebastián, en otras ocasiones denominada "Universidad» en los documentos y más excepcionalmente con el nombre de «Pueblo».

\section{LAS ACTIVIDADES POLITICAS DE LA «COMUNIDAD» $Y$ «UNIVERSIDAD»DE SAN SEBASTIÁN.}

\section{Monarquia y concejos vascos durante el siglo xV}

Los Reyes Católicos habían impulsado en el País Vasco una política de control de los municipios a través del Capitulado vitoriano de 1476 en la provincia de Álava y mediante las Ordenanzas de Chinchilla de 14831487 en el Señorío de Vizcaya ${ }^{3}$. La provincia de Guipúzcoa no quedó al margen de este proyecto político, por supuesto visto todo ello a posteriori. Ya Enrique IV había potenciado las Hermandades frente a la organización piramidal de la sociedad guipuzcoana estructurada principalmente en torno a dos bandos: Oñacinos y Gamboínos. Fernando e Isabel, continuando

2 La simple consulta de los Boletines de Estudios Históricos de San Sebastián pone de manifiesto la existencia de numerosos artículos cuyo peso fundamental se encuentra en los siglos XIV y XV, fruto sobre todo del mayor volumen de documentación conservada.

3 Véase sobre este tema WV.AA., Vizcaya en la Edad Media. Evolución demográfica, económica, social y politica de la comunidad vizcaína medieval. Bilbao 1985, 4 vols.; DíAz DE DURANA, J. R., "La reforma de los Reyes Católicos y la consolidacion de las oligarquías urbanas: $E$ Capitulado vitoriano de 1476 y su extensión por el Nordeste de la Corona de Castilla», La Formación de Álava. Comunicaciones. Vol. I, Vitoria 1985, págs. 213-236. 
con dicha política, pretendieron evitar que los «parientes mayores» de Guipúzcoa tuvieran acceso de una u otra forma al control del poder municipal y sobre todo, con el apoyo de ciertos sectores sociales, que la adscripción de las personas a uno u otro bando fuera requisito imprescindible para acceder a los oficios concejiles ${ }^{4}$.

En este sentido prohibieron los sistemas electorales que se hicieran a partir de la pertenencia a uno y otro bando o cuyos oficiales estuvieran «atreguados» o hubieran realizado algún juramento de fidelidad a dichos linajes. El ejemplo de la villa de Vergara, donde Ozaetas y Gavirias todavía a fines del siglo xV se alternaban en el poder, es suficientemente elocuente a este respecto. Pero lo mismo podría decirse de lo acontencido en la villa de Mondragón entre los linajes de las familias Guraya y Bañez e incluso en la villa de Oñate (Garibay-Uribarri), señorío de los Guevara ${ }^{5}$.

La crispación política existente en la Provincia de Guipúzcoa durante el siglo XV permitió a los reyes profundizar en la política anunciada anteriormente, sirviéndose de las protestas de todos aquellos que no estaban conformes con la gran influencia alcanzada por los «parientes mayores» directamente o a través de sus atreguados en las villas, bien porque les excluía a ellos o bien porque el sistema de bandos generaba más tensiones y diferencias entre los habitantes de estas localidades que elementos favorecedores de la integración de la comunidad. En definitiva, el final de los enfrentamientos entre los grupos banderizos podría contribuir en favor de una mayor paz social, en favor de un mejor desarrollo de las actividades económicas, de una mayor canalización de las fuerzas sociales en una mejora de la producción y en suma de un nuevo reequilibrio social.

Asimismo esta pretensión por parte de la administración de lograr la pacificación de una sociedad ciertamente muy divida y conflictiva, ofrecía

4 Las ordenanzas de la hermandad de Guipúzcoa de 1463 eran muy explícitas y conciuyentes en este sentido. Véase sobre este tema ARocenA, I., Oñacinos y Gamboínos. Introducción al estudio de la Guerra de bandos. Pamplona 1959.

5 BasternetXeA, A., Bergara: Hiria erdi aroan. Bergara 1991; Ayerbe Iríbar, M. ${ }^{2}$., Historia del Condado de Oñate y Señorío de los Guevara (siglos XI-XVI). Aportación al estudio del régimen señorial en Castilla. San Sebastián 1985, 2 vols.; DíEZ DE SALAZAR, L. A., "Régimen municipal en Guipúzcoa (siglos XV-xvI)", Cuadernos de Sección. Derecho. San Sebastián 1984, págs. 77-129. Un estudio interesante sobre los grupos dirigentes guipuzcoanos es el realizado por TENA GARcía, M $M^{\text {a }}$ S., "Enfrentamientos en el grupo social dirigente guipuzcoano durante ef siglo XV», Studia Historica, Vol. III, 1990, págs. 139-158. Véase a su vez García dE CoRTÁzAR, J. A., «El fortalecimiento de la burguersía como grupo social dirigente de la Sociedad Vascongada a lo largo de los siglos XIV y XV", La Sociedad vasca rural y urbana en el marco de la crisis de los siglos XIV $y$ XV. Bilbao 1975, págs. 283-312. 
ventajas a la propia monarquía, pues podría posibilitar que el comercio de la lana castellana hacia Flandes tuviera menores trabas en su desplazamiento o que los productos de importación procedentes de Flandes, Francia, Inglaterra, etc. vieran favorecido su traslado a su paso por la provincia de Guipúzcoa. Sin embargo, también otros sectores sociales y económicos de la Corona de Castilla se beneficiarían de una relativa pacificación de este territorio. En particular los mercaderes burgaseles, pero asimismo la nobleza propietaria de grandes rebaños de ovejas. Al fin y al cabo era su lana la que era mercadeada por los mercaderes castellanos y llevada por los transportistas, en no pocas ocasiones vascos, hacia Flandes. Además tanto mercaderes como nobles eran unos de los principales consumidores de las mercancías importadas.

La monarquía de la Corona de Castilla se sirvió para ello en Guipúzcoa de la institución del Corregimiento. Los corregidores fueron convertidos por ésta en los delegados encargados del buen cumplimiento de las órdenes reales en la provincia, al mismo tiempo que en ocasiones, precisamente por la fuerte división interna existente en las villas guipuzcoanas, fueron considerados por los vecinos de algunas de estas poblaciones en una especie de jueces árbitros con autoridad suficiente como para dictar resoluciones que resolvieran las diferencias entre sus miembros ${ }^{6}$.

\section{Los límites del poder concejil o la fuerza de la protesta de la Comunidao' de San Sebastián}

Poder y sociedad son elementos complementarios. Aquellas personas que llegan a alcanzar un cierto dominio político sobre el resto de la población están necesariamente obligadas en cualquier sociedad a establecer unas determinadas relaciones con el resto de la comunidad sobre la que ejercen dichas funciones. En el caso que nos atañe, los alcaldes, regidores y oficiales de la villa de San Sebastián ejercen una prevalencia de mando sobre el resto de la población mediante la adopción de acuerdos concejiles que, si bien han sido tomados exclusivamente por un concejo reducido, pretenden obligar a toda la comunidad de los vecinos.

6 Orella, J. L., El Delegado del Gobierno Central en Guipúzcoa. Estudio Histórico-jurídico del Corregidor Guipuzcoano durante el reinado de Isabel la Católica (1474-1504). San Sebastián 1987. Ello no impidió que durante el siglo XV algunos corregidores fueran seriamente protestados por numerosas villas y en particular por las Juntas Generales de la Provincia de Guipúzcoa. Incluso los Reyes Católicos llegaron a establecer una normativa precisa sobre la forma de nombramiento de los corregidores, otorgano ciertas prerrogativas a la Provincia. Véase INSAUSTI, S., "El corregidor castellano en Guipúzcoa (siglos XIV-XVI)», BRSVAP, XXXI, 1975, págs. 3-32. 
Evidentemente la mayoría de los habitantes de la villa quedaba fuera del juego político, o dicho de otra manera, no participaba en absoluto en las decisiones adoptadas por el ayuntamiento.

Es cierto que las elecciones al concejo eran anuales, pero no lo es menos la existencia de un sistema electoral cerrado que teóricamente beneficiaba tan sólo a aquellas familias que para el año 1489, fecha de la confección de las ordenanzas municipales, habían sabido o tenido la oportunidad de estar presentes en el poder concejil. Basta echar una ojeada a las ordenanzas para comprobar cómo los oficiales del año anterior se reservaban numerosas prerrogativas en el proceso electoral ${ }^{7}$. Pero además sólo tenían oportunidad de ocupar estos cargos personas «abonadas», es decir, con cierta solvencia económica.

En estas circunstacias no resultaba sencillo que existiera en la villa un trasvase de las ideas e intereses de la comunidad hacia las esferas del poder municipal. La actuación de este último también se debe mover en nombre del bien general, según se recoge en las ordenanzas municipales, pero es fácil entender que al pertenecer básicamente a un estrato elevado de la población sus ideas sobre el bien general coincidan en no pocas ocasiones más con sus intereses particulares -económicos fundamentalmente-que con los de los grupos de población con menor capacidad adquisitiva - pescadores, obreros, artesanos, campesinos, etc.-. Está en juego, por tanto, una cuestión fundamental: el cumplimiento de las leyes concejiles por todos los habitantes de la villa de San Sebastián. Es decir, la obediencia a la ley y al acatamiento del derecho local. Los principios generales parecen sostener la necesidad de que todos los vecinos cumplan con las ordenanzas municipales, realizadas presuntamente en beneficio de todos los habitantes. El poder se legitima con la puesta en práctica de las normas de derecho establecidas.

En la práctica de la vida política de la villa de San Sebastián se podrá comprobar la protesta constante de la Comunidad en contra de la actuación de los oficiales concejiles en determinados apartados, contra algunos de sus acuerdos o en contra de la interpretación que hacían de algunos capítulos de sus ordenanzas. El derecho local era con frecuencia contestado por no pocos vecinos y también el poder municipal. Precisamente porque en el derecho se regulan los mecanismos de las estructuras de poder y porque a través de su normativa se conforman unas determinadas

Véase Banús y Aguirre, J. L., «San Sebastián en el tránsito de la Edad Media a la Moderna. Con algunas apuntaciones de tiempos anteriores y posteriores", BEHSS, 1987, (21), págs. 1181. 
jerarquías posicionales de dominación entre los grupos de la población. El derecho no será en sí mismo un elemento exclusivo de las oligarquías locales, pero al ser éstas quienes controlen el poder de la villa tendrán unas mayores posibilidades de interpretarlo de manera práctica en su propio beneficio.

Así pues, un sistema político tan cerrado exigía una enorme dosis de comprensión y flexibilidad a los oficiales del concejo, si no querían que, en un momento dado, el pueblo, ante una política excesivamente exclusivista, acabara protestando de una manera desairada, ante la imposibilidad de hacer escuchar sus demandas. Finalmente se hizo necesario, como en muchas otras villas y ciudades de la Corona de Castilla, abrir una válvula de escape para el resto de la población, a través de la cual la comunidad pudiera disentir de las decisiones acordadas por los oficiales del concejo, controlar de algún modo sus actitudes e incluso pleitear contra dichos oficiales ante otras instancias político-administrativas superiores: el corregidor, el Consejo Real, etc.

Nació así una institución que se iba a encargar de velar por los intereses de la comunidad, entiéndase, por los de aquellas personas que no tenían posibilidad de acceder a los oficios concejiles por la existencia de un sistema electoral cerrado a una minoría y mantenido en líneas generales por la propia administración general de la Corona de Castilla ${ }^{8}$. Esta institución recibió el nombre de comunidad o universidad. Su representación la ejercerán diputados y procuradores nombrados al efecto para proteger sus intereses, frente a la posible agresión de los oficiales del concejo, cuando apoyando una determinada política municipal gravaban económicamente de manera particular a la comunidad, frente a los excesivos gastos del concejo cuyas repercusiones recaerían a continuación, sobre todo el pueblo mediante la solicitud de mayores tributos o también frente a la potencial corrupción y abuso de poder de los oficiales.

Esta institución, cuyos orígenes no conocemos por falta de pruebas documentales, está comprometida en los movimientos asociativos de la baja Edad Media (bandos, cofradías, etc.) ${ }^{9}$. Las dos iglesias de San Se-

a Monsalvo Antón, J. M. a El sistema concejil. El ejemplo del señorío medieval de Alba de Tormes y sus concejo de villa y Tierra. Salamanca 1988; MONTERO TEJADA, R. M. ", «La organización del Cabildo de Jurados de Toledo (1422-1510)». Espacio Tiempo y Forma. Serie lil, núm. 3. Madrid 1990, págs. 213-258; López VILLALBA, J. M., «El cuaderno de condiciones del común de Guadalajara de 1405”, Espacio, Tiempo y Forma. Madrid 1990, págs. 121-153; AsENJo GoNZÁlEZ, M. ${ }^{a}$, Segovia. La ciudad y su tierra a fines del medievo. Segovia 1986.

9 Mucho más se sabe sobre los prebostes de San Sebastián y sus tensas relaciones con el concejo. Véase Banús Y Aguirre, J. L., «Prebostes de San Sebastián: Los Mans y Engómez", BEHSS (1971), 13-70, (1972), 11-52. Los prebostes de San Sebastián fueron bastante protegi- 
bastián fueron las unidades territoriales sobre las que se fundó. En estos casos las circunscripciones parroquiales superan los marcos estrictamente religiosos y espirituales para adentrarse en el terreno de lo político. La propia denominación de la institución, "comunidad» o «universidad» demuestra sus pretensiones generales para toda la comunidad de los vecinos de San Sebastián.

Ello significa, en particular, la defensa de los intereses de los grupos con menor capacidad económica de la villa (medianos y pequeños). Pero, sobre todo, como tendremos ocasión de comprobar durante el desarrollo y estudio de los acontecimientos de los años finales del siglo xV, la «comunidad» es la antimonia de los oficiales concejiles. En definitiva, forman parte de ella aquéllos que no ocupan cargos en la administración concejl. Esto, no quiere decir, sin embargo, que algunos sectores del poder concejil no pudieran interferir ocasionalmente en dicho movimiento.

Pues bien, las relaciones entre la "comunidad» y los oficiales concejiles de la villa de San Sebastián adquirieron unos tintes peculiares en función del propio contexto geo-histórico de esta localidad. La situación de la villa en la frontera con el Reino de Francia y su incardinación en el entorno de las luchas banderizas vascas posiblemente sean dos elementos cruciales para comprender las actitudes políticas de Isabel y Fernando, reyes de la Corona de Castilla, de sus corregidores en Guipúzcoa, de los oficiales concejiles y de la propia Comunidad. Todo el último tercio de siglo $x v$ está repleto de alusiones al enfrentamiento entre los oficiales concejiles y la comunidad de San Sebastián. Las manifestaciones hicieron acto de presencia, no pocos pleitos se tramitaron a través de las correspondientes instancias judiciales y las acusaciones recíprocas de todo tipo quedaron recogidas en algunos documentos ${ }^{10}$.

dos por los monarcas castellanos, de hecho el prebostazgo acabó estando en manos de una familia, al contrario de lo dispuesto en el fuero de fines del XII. En no pocas ocasiones estuvieron enfrentados con el concejo de San Sebastián y con los vecinos, entrando en un cierto declive el auge de esta familia en época de los Reyes Católicos, según dicho autor.

${ }_{10}$ Otros estudios centrados en localidades castellanas evidencian la pujanza de este tipo de comunidades. Así el caso de Valladolid ha sido estudiado por Rucouol, A., «Valladolid, del Concejo a la Comunidad", La ciudad hispánica durante los siglos XIII al XVI. Madrid (1985), 745772; para el caso de Burgos resulta de gran interés las ideas y reflexiones expresadas en su artículo por Pardos MARTínez, J. A., «Constitución patricia» y «Comunidad» en Burgos a finales del siglo xv (Reflexiones en torno a un documento de 1475)», La ciudad hispánica... 545-579. Este autor sostiene la existencia de una reciprocidad de intereses políticos entre los oficiales concejiles y los Reyes Católicos, Isabel y Fernando, lo que acabará con la marginación de la "Comunidad" y de gran parte de los logros anteriores. Véase a su vez las sugerentes consideraciones de LADERO QUESADA, M. A., "Corona y ciudades en la Castilla del siglo XV", en La España Medieval. V. Estudios en memoria del profesor D. Claudio Sánchez Albornoz. Madrid (1986), 531-574. 
a) Las conflictivas elecciones municipales

Uno de los asuntos que con más frecuencia aparece en la documentación del último cuarto del siglo XV es el de las elecciones concejiles. La intervención de la "administración central» en estos casos suele ser justificada como una forma de mantener la paz y el orden en la villa. Paz y orden que se habrían visto alterados por las tensiones surgidas cuando se procedía al nombramiento de los nuevos oficiales del concejo. En ocasiones se llega a afirmar que esta compleja situación, derivada de la división de ideas y opiniones existente en la población, había dado origen al surgimiento de movimientos de protesta. Por supuesto, estos «alborotos" solían ser utilizados por la administración como excusa para intervenir directamente, corregir y reconducir a su manera la situación.

En relación con esta problemática las diferencias entre la comunidad de San Sebastián y los oficiales concejiles están perfectamente documentadas desde 1488. Este año el alcalde Pedro Martínez de Igueldo remitía una queja ante el Consejo Real en la que protestaba del trato que había recibido por el pesquisidor Diego Arias de Aranya. Según se desprende de la lectura del documento, el pesquisidor había sido enviado por los reyes Isabel y Fernando a la villa de San Sebastián, con el fin de investigar los problemas existentes entre los vecinos y para ello se determinó que se suspendiera la alcaldía, el prebostazgo, etc., mientras llevara a cabo la investigación. No obstante, el concejo de San Sebastián se reunió para nombrar los nuevos oficiales y con el consentimiento del pesquisidor se acordó que el nuevo alcalde, una vez finalizada la pesquisa, habría de ser Pedro Martínez de Igueldo. Éste, según sostiene en su defensa, tomó residencia en el cargo con el beneplácito de Diego de Arias de Aranya.

A pesar de todo surgieron algunos debates entre ambos personajes y el pesquisidor amenazó al alcalde, lo apresó, coaccionó a los otros oficiales para que no le pagaran a éste los gastos ocasionados por él en la Corte, le prohibió que usara del oficio de alcaldía y nombró otro alcalde en su lugar, además de desterrarle durante tres meses de la villa de San Sebastián. No se sabe cuál fue el motivo por el que se inició esta investigación, pero es evidente la existencia en la villa de un enfrentamiento entre algunos sectores de la población. En todo caso, los Reyes Católicos ordenaron el 18 de enero de 1488 al corregidor, Juan de Ribera, que 
estudiara el caso y restituyera en su honor al alcalde Pedro Martínez de Igueldo, si descubría que éste tenía razón ${ }^{11}$.

Todavía el 4 de noviembre de 1488 los oficiales de San Sebastián solicitaban permiso a los Reyes Católicos para poder elegir los nuevos oficiales del año 1489. A través de una carta real se habían suspendido las ordenanzas de la villa y particularmente esto incidía de una manera inmediata en el capítulo referente a la elección de los nuevos oficiales durante el tercer día de la Navidad. En esta ocasión los Reyes concedieron permiso para que se llevara a término la elección por los alcaldes y oficiales del año 1488. Ya en este documento se ordena que los nuevos oficiales han de ser «hábiles y suficientes», actuar al servicio del rey y del bien de la villa, así como que se les tome juramento de que desempeñarán sus cargos bien, fielmente y sin parcialidad alguna. Por primera vez, se hace alusión a que los oficiales de la villa no sigan parcialidades, pero nada nos permite confirmar que con ello se quiera aludir en concreto a posibles conexiones de los linajes "donostiarras" con los otros bandos guipuzcoanos ${ }^{12}$.

Las primeras ordenanzas municipales de San Sebastián conocidas fueron confirmadas por los Reyes Católicos, Isabel y Fernando, el 7 de julio de 1489. Los procuradores de San Sebastián, el bachiller Martín Ruiz de Elduayen y Miguel Ochoa de Olazábal solicitaron a los Reyes Católicos y a su Consejo que dictaminaran sobre el contenido de las ordenanzas confeccionadas en tiempos del juez pesquisidor, el bachiller Diego Arias de Anaya. Estaba claro que algunos sectores de la población no estaban de acuerdo con todo el articulado de las ordenanzas. La circunstancia de que se aclare en el documento que los cambios se efectuaron en presencia de los procuradores citados parece indicar que ambos representaban a los grupos de población disconformes con la forma en que había sido redactado el primer capitulado. Lamentablemente no se señalan en el texto conservado las alteraciones $o$ añadidos al primer cuaderno de ordenanzas.

Este texto se ocupa de regular detalladamente numerosos aspectos de la vida municipal relacionados con el aprovechamiento económico de la vida municipal relacionados con el aprovechamiento económico del término jurisdiccional de San Sebastián en las diferentes ramas de la economía, el comercio, la artesanía, la pesca, la agricultura, la ganadería, etc. La política de abastecimientos de la villa y la preocupación por la 
seguridad e higiene del núcleo urbano son también puntos cruciales de estas ordenanzas, en los que se detuvieron los legisladores. Uno de sus capítulos más importantes es el dedicado a la organización concejil, su aparato administrativo, el sistema electoral, el control de la actuación de todos los oficiales concejiles, etc.

En cualquier reglamentación interna de los concejos es fundamental la regulación de las formas de acceso a ocupar los oficios políticos de una localidad. No menos trascendental es la fijación por escrito de las funciones y obligaciones de los oficiales concejiles, así como del salario que lleva parejado cada cargo público. Las ordenanzas de San Sebastián ofrecen todo tipo de detalles en este terreno, síntoma muy probablemente de la existencia de serios debates en el seno de la población por este motivo. De la lectura de las ordenanzas se deduce que el concejo estaba compuesto por dos alcaldes y 12 oficiales. Estos últimos son dos jurados mayores, dos guardapuertos, cuatro regidores y cuatro jurados menores. En otras ocasiones a estos 12 oficiales se les califica indistintamente como jurados o como regidores.

Las elecciones se desarrollarían dos días después de transcurrida la Navidad de la siguiente manera. El escribano del concejo debería de entregar "charteles» a 10 miembros del concejo, los dos alcaldes y ocho jurados - no toman parte en la elección los jurados menores-, y a otras «muichas» personas "de los principales vecinos» de la villa. Al día siguiente, en la festividad de San Juan, se reunirían todos ellos en la casa concejil de Santa Ana, tras haber escuchado misa en la iglesia de Santa María y una vez que se hubiera notificado el acto de forma pública mediante el repique de las campanas. A continuación los diez oficiales debían jurar ante la cruz y los santos evangelios que no actuarían movidos por interés particular alguno ni por «parcialidad».

Cada oficial, en un lugar apartado, juntamente con el escribano nombraría una persona «buen nombre e de buena fama, conciencia e avilidad» que sería puesta por escrito en un «cartel» por el escribano. Los oficiales del concejo cuyo mandato finaliza no pueden nombrarse a sí mismo como electores. El escribano haría otros ocho «carteles", la mitad de los cuales contendría la palabra elector. Después y en presencia de todos se introducirían en dos ollas diferentes o en dos jarros cubiertos, por un lado los papeles que contenían el nombre de las personas a elegir y por otro los papeles en blanco o con la palabra elector. Una vez realizado este proceso se llamaría a dos niños «sin sospecha» que con los brazos remangados sacarían cada uno de ellos de la olla que le habrían asignado un «cartel». Uno de los niños mostraría el cartel al escribano y a otra persona y el otro a otras dos personas. De esta forma hasta que coincidieran los nom- 
bres de cuatro personas con los carteles que tenían escrita la palabra elector. Las cuatro personas elegidas mediante este sistema se convertirían en los cuatro electores o personas encargadas de designar a los nuevos oficiales concejiles.

Estos cuatro electores, tras jurar que actuarían correctamente y sin parcialidad, guardando el servicio de los reyes y el bien público de la villa, comenzaban a nombrar a los nuevos oficiales. Los electores no pueden proponerse a sí mismos como oficiales para el nuevo ayuntamiento. Para la elección de los dos alcaldes cada elector en forma secreta nombraría a dos personas. El escribano hacía cuatro carteles con las parejas de nombres dadas por los electores y a aquella que le correspondiera por sorteo obtendría el oficio de la alcaldía. Este mismo procedimiento se seguiría para la elección de los dos jurados mayores, de los dos guardapuertos, de los cuatro regidores, de los cuatro jurados menores o «cogedores de pecho» y del mayordomo o bolsero del concejo. Para la elección del procurador del concejo cada elector nombraría a una persona, siendo el sorteo posterior quien determinaría la elección ${ }^{13}$. Se trata de un sistema electoral restringido a un sector muy pequeño de la población, como ya ha sido señalado unas líneas antes. Ya en esta ocasión se dieron medidas en contra de todos aquellos que reuniéndose bajo la forma de cofradías, ligas o monipodios, se decía, alborotaran al pueblo o fueran contra lo acordado por los oficiales concejiles de forma escandalosa.

Pues bien, en 1491 el regimiento de San Sebastián consideró que las retribuciones recibidas por el desempeño de los oficios eran pequeñas y acordó incrementar las cantidades a percibir. Ello significaba presumiblemente un aumento de la contribución de los vecinos al concejo, lo que podría ser motivo suficiente para que los vecinos se movilizaran para impedir dicha circunstancia. En cualquier caso, los oficiales se dirigieron a los Reyes Católicos con el fin de recabar el permiso necesario. El 29 de enero de 1491 Isabel y Fernando ordenaron al Corregidor que estudiara el caso ${ }^{14}$.

El sistema electoral acabó convirtiéndose asimismo en uno de los «caballos de batalla» del "común» de la villa. La comunidad de San Sebastián fiscalizó en lo posible la actuación de los oficiales concejiles y no dudó

13 Antes de que se aprobaran las ordenanzas no eran infrecuentes los alborotos en la villa. AGSRGS, 12-VI-1489, fol. 299. Precisamente en esta época se subieron los jornales de los carpinteros y canteros, inmediatamente después de la quema de la villa de San Sebastián. AGSRGS 24-lll-1489, fol. 46.

14 AGSRGS 29-1-1491, fol. 203. 
durante el último tercio del siglo xv en elevar sus quejas ante la Corte. Una de las protestas más sonadas que llevó ante el Consejo real tiene que ver con su desacuerdo con el sistema electoral de los oficiales del concejo de San Sebastián. No es improbable que detrás de las diferencias existentes en el concejo a lo largo del año 1488 se encuentre la Universidad y hombres buenos de San Sebastián. Pero su presencia es innegable y segura en 1491.

El 22 de noviembre de dicho año los Reyes Católicos ordenan, ante la previsión de que se generaran debates entre el común y los oficiales, que el Corregidor juntamente con los oficiales del concejo nombre electores, encargados de elegir a los alcaldes, fieles y jurados entre todos los estados de la villa. No es fácil llegar a concretar lo que se entiende por "entre todos los estados de la villa», pero en cualquier caso parece desprenderse la idea de que todos los vecinos, pertenezcan a una u otra condición socio-económica, podían ser nombrados como oficiales del concejo. Del mismo modo, esta exigencia puede estar indicándonos la existencia de quejas por parte de un sector de la población que se siente marginado a este respecto. No se ha de olvidar, sin embargo, que el control de todo el proceso electoral quedaba en cierto modo en manos de electores nombrados por los oficiales salientes. Por tanto, las garantías reales para que la situación precedente se modificara no parecen ser en principio demasiadas ${ }^{15}$.

Unos días después, el 28 de noviembre, a solicitud de los procuradores de la Universidad de San Sebastian, los Reyes ordenan que los oficiales del concejo y aquéllos que se juraron con ellos paguen de sus propios bienes las costas del pleito que siguen contra la comunidad sobre el sistema electoral «syn los pagar de los propios nin faser repartimiento general en la dicha villa... ${ }^{16}$. Está claro que la «comunidad» ha comenzado a dar mucha importancia a las formas de acceso al poder municipal. De que unas personas $u$ otras ocuparan dichos cargos se derivaban distintas consecuencias. La "comunidad", no sólo había comprendido esta realidad, sino que además había decidido tomar cartas en el asunto como tal «comunidad».

\footnotetext{
15 AGSRGS 22-XI-1491, fol. 87. Con esta misma fecha se tiene constancia de la existencia de un documento en la villa de San Sebastián, en la actualidad desaparecido, en el que se hace alusión a unas nuevas ordenanzas dadas por los Reyes Católicos en relación con las elecciones, las tasas, las imposiciones y las carnicerías. Véase BANús y AGuirRe, J. L., El archivo quemado: inventarios antiguos del acervo documental de la M.N. y M.L. Ciudad de San Sebastián antes de la destrución de 1813. San Sebastián 1986, pág. 115.

16 AGSRGS 28-XI-1491, fol. 218.
} 
Al día siguiente, el 29 de noviembre, se redactaba otra carta en la que los Reyes sentenciaban que el corregidor estuviera presente en la elección de los oficiales de 1492 con el fin de evitar diferencias y debates. Se manda a su vez que la elección se realice de acuerdo con las ordenanzas y que posteriormente se confirmen los nombramientos por el Corredigor. Asimismo se le recuerda a éste que los oficiales tienen la obligación de ocupar y desempeñar el cargo durante todo el año, haciéndose alusión a la existencia de algunos intentos por parte de la Universidad para que los oficiales dejaran sus oficios antes de haber cumplido el año para el que habían sido designados ${ }^{17}$. Este es un síntoma demasiado evidente de las enormes diferencias y de los enfrentamientos entre comunidad y oficiales concejiles por diversos motivos, si bien uno de ellos sería probablemente el haberse subido a sí mismos los salarios.

Pero, sin duda, aparece ahora por primera vez un cambio notable en relación con el proceso electoral de la villa, si nos atenemos al contenido de las ordenanzas de 1489. En este documento se señalan con claridad las nuevas circunstancias en que se habrian de llevar a cabo las elecciones de los oficiales. Estos serían nombrados a partir del año 1493 por los procuradores de la Junta General, reunidos en la villa de San Sebastián. Los denominados comúnmente por la historiografía contemporánea como Reyes Católicos, isabel y Fernando, y su administración decidieron finalmente tomar cartas en el asunto, a tenor de las sentencias emitidas desde la Corte con su autorización.

Las novedades introducidas en 1492 a partir de los dictámenes reales son significativas. En primer lugar, la presencia del corregidor será necesaria para que la elección tenga validez, en segundo lugar éste interviene en el nombramiento de los electores mediante su necesaria confirmación personal y en tercer lugar al año siguiente la elección deberá hacerse por los procuradores de la Junta General de Guipúzcoa. Precisamente a través del tercer punto se hacía una concesión a lo demandado por los procuradores de la comunidad de San Sebastián, se alteraban las ordenanzas anteriores de 1488 y 1489 y ciertamente se evidencia la fuerza que estaba alcanzando el "común» en la villa.

La presión de la "comunidad" habría convertido a este «movimiento popular" en un poder paralelo al de "concejo cerrado", al amparo del beneplácito del Consejo Real, institución que no tuvo peros en favorecer algunas de sus solicitudes. De esta forma no sólo se obtiene la impresión

17 AGSRGS 29-X1-1491, fol. 45 . 
de que la presión del «común» fue fundamental para conseguir algunas de sus reivindicaciones, sino también se aprecia que el verdadero poder político se encontraba en última instancia en la Corte, que con sus sentencias podía controlar y condicionar la actuación de los poderes municipales.

En mi opinión, el favorecimiento de la administración monárquica castellana al "común» de San Sebastián, se ha de comprender asimismo en función de la propia situación estratégica de la villa, en especial, por tratarse de una villa fronteriza con los reyes de Francia, a la que se pretende proteger políticamente. No en vano, el ejército francés había asediado a esta población y estas fronteras se habían visto invadidas por el mismo por estas fechas en más de una ocasión.

El aparente endurecimiento de las sentencias reales contra los oficiales concejiles significa fundamentalmente un intento de controlar sus actividades más que una persecución tenaz y obcecada contra los poderes oligárquicos locales, un intento por evitar que nazcan focos de tensión en una villa importante para los intereses generales de la Corona, por ser un núcleo de población con una densidad demográfica considerable en la zona, por la trascendencia de su puerto desde un punto de vista estrictamente económico y por la complejidad de las relaciones políticas internacionales entre Castilla y Francia. De otro lado, la oligarquía local siguió controlando los oficios concejiles, si bien esta política real afectó positivamente al conjunto de la población, la "comunidad», cuyas demandas fueron en parte escuchadas, que era quien más sufría las dificultades generadas por la situación fronteriza de la villa.

En suma, el Consejo Real, se había acabado convirtiendo en el árbitro de los conflictos internos existentes entre los vecinos de San Sebastián. Lo permitía el reconocimiento por todas las partes de esta institución como último exponente de la justicia Real. Pero el propio recurso constante a esta institución por los vecinos de la villa evidencia el interés de estos grupos por obtener ventajas políticas, económicas o sociales mediante las resoluciones jurídicas dadas desde la administración. Expresión a su vez de la confianza depositada en las estructuras judiciales en particular por los grupos sin presencia en la institución concejil.

\section{b) Las sentencias de 1492}

1492 ha pasado a los anales de la historia de la Corona de Castilla como un año excepcional por la serie de acontecimientos históricos de carácter universal que en el mismo se produjeron. La llegada a América 
por Cristóbal Colón, la conquista de Granada y la expulsión de los judíos. No obstante, estos tres eventos históricos, por transcendentes que en sí mismos sean, no pueden hacernos olvidar otros hechos históricos cuya significación no fue menor para aquellas localidades en que tuvieron lugar. La administración de la monarquía de la Corona de Castilla se ocupaba de los "grandes" asuntos y de los "pequeños" asuntos generados en cada uno de los puntos de su dominio. Una de estas preocupaciones fue la de intentar resolver las disputas, a veces agrias, entre los oficiales del concejo y la «comunidad» y «universidad» de hombres buenos de San Sebastián.

Sin duda alguna, a pesar de todas las referencias documentales señaladas anteriormente y de su notable información, hasta 1492 nuestro conocimiento de los acontecimientos acaecidos en la villa de San Sebastián no es lo bastante completo. Es decir, las relaciones entre la Comunidad y los oficiales del concejo aparecen como rápidas pinceladas sobre un lienzo todavía no acabado. Tal vez la imagen mejor dibujada sea la que enfrentó a la "comunidad" y a los oficiales concejiles por la manera en que habían de practicarse las elecciones municipales, pero se nos esconden los orígenes reales del conflicto, -o lo que es lo mismo, dónde puede encontrarse la causa de esta larga rivalidad entre ambos grupos-, la forma y la violencia con que se desarrolló, muy poco sabemos sobre quiénes pudieron ser los instigadores del mismo y tampoco se sabe nada de las conexiones del aparentemente tema central del debate, el sistema electoral, con otras cuestiones económicas o sociales. Todos estos interrogantes no se podrán resolver con la documentación conservada de este año, pero las fuentes de 1492 permitirán apreciar unos esbozos cada vez más precisos y claros.

La oposición a la existencia de bandos por parte de la «comunidad» es una de las piezas dignas de ser tenida en consideración. En esta línea, el «común» no hacía sino identificarse con los proyectos políticos mantenidos por la monarquía castellana. ¿Tal vez, habría que preguntarse si formaba parte de una estratagema o por el contrario coincidía plenamente con sus propios intereses? Idea esta última que nos parece la más razonable a tenor de la escasa capacidad decisional que tenían las capas populares no nobles entre los bandos guipuzcoanos. Pero tampoco habría que extrañarse de que la «comunidad» acusara de banderizos a aquellas personas de las que desconfiaba o a aquellas que podían perjudicar sus propósitos y sus objetivos. En este último caso, el fin no podía ser otro sino el de descalificar a estos personajes.

De hecho, en la defensa de sus intereses los procuradores del común llegaron a acusar a algunas personas de "banderos", tal como los de- 
nominan algunos textos, o banderizos. Estos son los casos de los bachilleres Martín Ruiz de Elduayen y Juan Sánchez de Elduayen, personas a las que se pretendía impedir que fueran letrados del concejo mediante dicha acusación ante la Corte. Los Reyes Católicos, como en otras ocasiones, emitieron una carta de fecha 12 de abril de 1492 en la que se ordenaba al corregidor que iniciara una investigación sobre este asunto ${ }^{18}$. La Comunidad ya había tenido diferencias con Martín Ruiz de Elduayen por el salario que percibiría por su trabajo de letrado. Todo parece indicar que el objetivo fundamental era controlar en cierta manera la influencia que tenía esta familia en la villa, así como los gastos que el primero de ellos decía realizar en nombre del concejo. De la documentación puede deducirse que la comunidad pretendía limitar las actitudes públicas de los miembros de esta familia para evitar presuntos abusos de poder.

18 AGSRGS 12-IV-1492, fol. 293. Sin embargo, estos personajes tuvieron peso en la vida económica y política de la villa durante estos años. Ya antes Martín Ruiz de Elduayen había sido alcalde durante algunos años (1475 y 1489) y su hermano Vicente de Elduayen era un importante mercader, que ocasionalmente parece no dudar en acudir a la piratería con el fin de lograr pingües beneficios. Asimismo el bachiller Juan Sánchez de Elduayen, hermano de los anteriores, fue alcalde de San Sebastián en 1480. AGSRGS 4-X-1476, fol. 679, 13-VI-1480, folios 58,257 y 186 . Asimismo el bachiller Martín Ruiz de Elduayen tenía intereses en algunas ferrerías guipuzcoanas, así como sus hermanos Vicente y Juan, del mismo modo que algunos «Parientes Mayores" de Guipúzcoa. Véase Tellechea IDígoras, J. I., "Ferrerías Guipuzcoanas a fines del siglo XV. Un importante documento inédito del Archivo de Simancas". BRSVAP, XXXI, 1975, págs. 81-111 y DíEz DE SALAZAR, L. M. ", "Ferrerías de Guipúzcoa en la cuenca del Urumea (s. XV|): BEHSS, núm. 25. San Sebastián 1991, págs. 131-183. Entre 1493 y 1495 se seguían pleitos en la Corte por el concejo y la comunidad de San Sebastián contra el bachiller Martín Ruiz de Elduayen por ciertos gastos que éste había hecho en el seguimiento de cierto pleito. Su propio hermano, Juan Sánchez de Elduayen, le defendía y era su procurador. (A.R. Chancillería de Valladolid, Pleitos Civiles, Zarandona y Wals, olvidados c. 1082-6). No resulta extraño que el 12 de septiembre de 1492 Marín Ruiz de Elduayen solicitara ante los Reyes la liberación de la obligación de ser alcalde u oficial del concejo o procurador de las villas guipuzcoanas. En su opinión esta situación le estaba generando más inconvenientes que ventajas. Los Reyes Católicos salieron en su favor «sepades quel bachiller Martin Ruys delduayen nos fiso relaçion por su peticçion que ante nos en el riuestro consejo presento desiendo que vos la dicha junta $e$ procuradores e villa de Sant Sebastian algunas veces le abeys nonbrado por procurador e mensajero para benir a a nuestra Cort e a otras partes e aunque se a querido escusar nunca gelo aveys consentido e que vos le le abeys elegido e elegis otras veses por el alcalde e regidor e a otros ofiçios en lo qual dis que el ha resçebido danno e nos suplico que le fisieremos merçed para que fuese escusado que contra su voluntad non pudiese ser apremiado nin conpelido a absetar ninguno de los dichos ofiçios nin cargos de mensajero nin procurador contra su voluntad o commo la nuestra merçed fuese e nos por faser bien e merçed al dicho bachiller tovismolo por bien.... (AGSRGS IX-1492-208). En 1496, el mercader Vicente de Elduayen era uno de los alcaldes de la villa, el otro era Lorenzo de Montaot (A.R. Chancillería de Valladolid. Reales Ejecutorias, I. 95-1). En relación con los oficiales del concejo de San Sebastián véase Banús y AguiRRE, J. L., "Aicaldes capitulares de San Sebastián (1286-1813)". BEHSS San Sebastián 1975, págs. 11 y siguientes. 
El 26 de abril de 1492 se emite una carta cuyo contenido manifiesta con claridad la tensión y la rivalidad existente en la villa de San Sebastián desde el año 1488. Precisamente los alcaldes de 1489 -el bachiller Martín Ruiz de Elduayen y Miguel Ochoa de Olazabal-, los jurados mayores - Juan Martínez de Abarrasqueta y Martín Pérez de Poares-, los jurados regidores Domingo Martínez de Vagostra, Juan Martínez de Harastune, Pedro de Albis, Domingo de Rogorre, Cheneco de Uhacue y Juanito de Larrondoburto - y el escribano fiel - Martín Pérez de Allday - habian apelado ante la Corte por las acusaciones y perjuicios que les habían ocasionado los oficiales del año de 1490. Estos mismos afirman que durante su mandato se dictaron las ordenanzas municipales de la villa, sin duda con el fin de dar testimonio de la importante labor realizada para el buen gobierno y administración de la villa ${ }^{19}$.

¿Qué había sucedido para llegar a esta situación? Sencillamente que los nuevos oficiales consideraron que las cuentas presentadas no se habían hecho conforme a las ordenanzas y el bien público de la villa. Las cuentas fueron examinadas por Martín Ruiz Alzega, Juan Miguel de Zacaya, Pedro de Torraco, sastre, Miguel de Tolosa y los jurados mayores siguientes, Pedro Martínez de Igueldo, Juan Martínez de Lastro, Martín Ramos de Salvatierra y Pelegrín de Arpide, todos ellos carniceros.

Tras el examen correspondiente consideraron que había un fraude en unos 100.000 maravedís, que hicieron pagar «religiosamente» a los oficiales de 1489, no sin antes haberlos hecho meter en la «torre concejil», sin dar tiempo a que éstos apelaran de su determinación a quien tuviera lugar. Es significativo que entre los oficiales del año 1490 haya una importante presencia de carniceros. Se trata, por tanto, del enfrentamiento entre dos grupos con una presumiblemente elevada capacidad económica, enemistados entre ellos posiblemente por el acoso a que habían sido sometidos los segundos en 1489.

En este debate no entra en juego de manera directa la comunidad de San Sebastián, pero si de forma indirecta. De hecho, a instancias de ésta, se emite una carta real de fecha 28 de abril de 1492 por la que se prohíbe que los carniceros sean regidores, así como a aquellas personas que tengan algún interés en la carne o en los pesos de la carne ${ }^{20}$. La comunidad con la consecución de este derecho hacía un gran favor al ayuntamiento de 1489 -del que fue su alcalde Martín Ruiz de Elduayen-, pero el motivo por el que ésta protestaba no tenía nada que ver en esta 
ocasión con la existencia de una mejor o peor contabilidad municipal. La comunidad se queja de que durante los últimos años los carniceros eran regidores, tasándose los precios de las carnes a precios mayores de los debidos por estar éstos en el concejo, así como haciendo caso omiso a la posesión por algunas personas de pesas fraudulentas.

Todo indica, por tanto, que la comunidad se puso en contra de los carniceros no por el control a que habían sometido al regimiento de 1489 , cuanto por la subida del precio del abastecimiento de la carne ${ }^{24}$. A su vez no dudó en enfrentarse con los hermanos Elduayen, personas de las que la comunidad desconfiaba. Ciertamente esta familia no caía simpática a determinados sectores de la población de San Sebastián. En cualquier caso, este ambiente de enfrentamiento entre los concejos de 1489 y 1490 pudiera estar latente en la mayoría de los conflictos que se producen en la villa durante los años finales del siglo.

La «universidad» de San Sebastián pudo crecer y fortalecerse como freno a determinados acuerdos de los oficiales del regimiento, al amparo de estas crispaciones existentes en las cúpulas decisionales del poder concejil. En primer lugar, aunque no sea necesariamente éste el lugar de primacía que le corresponda, a consecuencia del desarrollo de una mayor conciencia social entre el conjunto de la población relacionada con la necesidad de contrarrestar ciertas arbitrariedades del regimiento. El 12 de abril de 1492 se volvía a instar al corregidor para que obligara a los oficiales del concejo a que pagasen de sus bienes los 7.160 maravedís de las costas originadas en el seguimiento del pleito por el "común y hombres buenos» de San Sebastián, a pesar de la apelación presentada por los alcaldes y regidores que se relacionan: Martín Pérez de Oquendo, Martín López de Amézqueta, Saobat de Arizmendi, Juan Bono Jaymar, Pedro de Villaviciosa, Pedro de Villarreal, Pedro de Segura, Arnalt Juan de Hireta, Lope de Arrazain y Juan de Illumbe ${ }^{22}$.

El 26 de abril se les ordena asimismo a los oficiales del regimiento que paguen al procurador de sus bienes "con aperçebimiento que vos fasemos que si se los pagaredes de los propios del dicho conçejo e republica del lo tornareys a pagar con el quatro tanto...". En segundo lugar, aspecto éste tan fundamental como el primero, porque el enfrentamiento surgido entre el "patriciado urbano" debió empujar circunstan-

21 Ya desde 1454 los vecinos de San Sebastián ponían sumo cuidado en fijar los precios de la carne con los carniceros que habian suscrito el contrato de arrendamiento de las carnicerías. Banús y Aguirre, J. L., El Archivo quemado..., pág. 11.

22 AGSRGS 12 -IV-1492, fol. 158. 
cialmente a algunos sectores de la oligarquía local a apoyar al "común» con el fin de arrinconar a sus presuntos adversarios políticos ${ }^{23}$.

Ciertamente a lo largo del mes de abril de 1492 se dictaron varias sentencias muy importantes para conocer en cierta manera qué era lo que estaba sucediendo en la villa de San Sebastián durante los tres úitimos años. Pero la información más completa procede de una carta emitida por los Reyes Católicos, de fecha 26 de septiembre de 1492, en la que se recogen las quejas y presuntos agravios recibidos por parte de la comunidad y hombres buenos de San Sebastián de los alcaldes, regidores y oficiales del concejo de la villa, cuyo procurador fue Fernando de Miranda. La Comunidad y los oficiales concejiles habian entablado un pleito en función de determinadas actuaciones del alcalde y los regidores. Minuciosamente cada parte expresa su punto de vista en relación con las diferencias existentes entre ambas y a continuación se emite sentencia definitiva $^{24}$.

Merece la pena detenerse a analizar los razonamientos ofrecidos por la comunidad y los oficiales, pues ello permite comprender no sólo el importante significado del enfrentamiento, sino sobre todo la capacidad de organización de la Comunidad, al mismo tiempo que se manifiesta el control que esta recién nacida institución - si se puede utilizar dicha expresión-, al margen propiamente del concejo, llegó a ejercer en algunas ocasiones sobre los alcaldes y el resto de los oficiales. En estos dimes y diretes de acusaciones mutuas aparece una defensa de la legalidad de las actuaciones llevadas a cabo por parte de los oficiales concejiles y la acusación de abuso de poder por parte de aquéllos que representan a la Comunidad.

El alcalde y los regidores solicitan la exención del pago de las costas de este pleito entre otras causas porque la Comunidad, actuando en contra de las ordenanzas, había realizado «ligas y monipodios secretos y públicos» provocando alborotos con el fin de «destruir» el regimiento y acabar con unas «justas ordenanzas». A su vez amenazan que de seguir así las cosas nadie querría aceptar los oficios de la villa. Por tanto, los oficiales comienzan por lanzar una muy dura acusación contra la parte contraria, sin duda, con el objetivo de impactar desde un primer momento a los jueces. La Comunidad es presentada como alborotadora y actuando de forma ilícita y sus métodos podrían tener serias consecuencias en lo que se refiere al sistema de gobierno municipal. Es evidente, que al afirmar

24 AGSRGS 26-IX-1492, fol. 308. 
que no encontrarían quien aceptara los oficios, están refiriéndose al pequeño grupo de familias que habitualmente controlan el poder municipal.

Los oficiales manifiestan su desacuerdo con las penas en que han sido condenados en sentencias anteriores. Afirman que habían actuado conforme a derecho en relación con la puja efectuada por las carnicerías, pues sólo cuando se rompió el contrato, que hasta la fecha tenían, sacaron a subasta el arrendamiento de la carnicería. La pena que se les había impuesto desde el Consejo por este motivo fue de 7.900 maravedís. Niegan haberse repartido entre ellos las rentas obtenidas del arrendamiento de la carnicería, así como que hubieran consentido que los carniceros utilizaran pesos falsos triplicando de este modo su ganancia. Es evidente que la "comunidad" presionaba para que el precio de los abastecimientos de la carne se abaratara o, al menos, no se incrementara. Los oficiales lógicamente, consideran que habían actuado correctamente al apelar sobre estas cuestiones ante la Corte por lo que no debían pagar las costas realizadas por el «común y hombres buenos».

«especialmente por quanto por la dicha carta aviamos mandado questoviese al sacar de los ofiçiales de la dicha villa el corregidor o su lugarteniente e los procuradores que en la primera junta que en la dicha provinçia se oviese de faser se juntasen e que ellos eligiesen et nonbrasen los alcaldes fieles et jurados et los otros oficios segund se devian nombrar por las hordenanças de la dicha villa et que en los suso dicho la dicha carta contenía manifiesta ynjusticia et agravio porque los tales procuradores vernian dadivados et rogados et eran di parçialidad et porque no solian venir a la dicha junta procuradores ynstratos ni tales que supiesen entender las hordenanzas nin lo a ellos mandado por la dicha nuestra carta et porque era dar cabsa que nunca los tales ofiçiales se sacasen porque seyendo y trenta procuradores et mas los que venian a la dicha junta non se podrian conformar para sacar los dichos ofiçiales et que asy mismo la dicha carta era agraviada porque desya que para el tomar de las cuentas et repartimientos del dicho conçejo que se llamasen dos 0 tres personas del comun de la dicha villa seyendo asy por hordenança de la dicha villa confyrmada y aprovada por nos commo por carta et provisyon de los reyes de gloriosa memoria nuestros progenitores et por constunbre antigua e ynmemorial..."

Es evidente que de la comparación del contenido de este texto con el de las ordenanzas de 1489 se aprecia una relativa pérdida de poder para los «viejos» grupos dirigentes en lo que se refiere al proceso de selección de los oficiales concejiles.

Exigen que la fiscalización de las cuentas municipales requiere la elección «por suertes» de cuatro hombres, que anteriormente tenían que prestar juramento delante del altar de San Juan de la iglesia mayor de la villa, así como lo hacían los alcaldes y los regidores. Sin embargo, sostienen, 
que sólo estuvieron presentes en el acto tres de los cuatro hombres buenos, sin que hubieran jurado con antelación su cargo. En definitiva, afirman que la forma en que habían sido hechas las cosas por la parte contraria no era conforme a derecho y que ellos tenían razones suficientes para manifestar su desacuerdo a través de las consiguientes apelaciones.

De otro modo, protestan de la prohibición que se les había impuesto de echar nuevas sisas que no rebasaran los 30.000 maravedís. Defienden la importancia de este sistema de recaudación para cuyo mantenimiento contaban con algunas cartas reales que les autorizaban a utilizarlo hasta dicha cuantía máxima de 30.000 maravedís ${ }^{25}$. Alegaban que era un sistema impositivo complementario con el sistema de los repartimientos solicitados a los vecinos según el volumen de su hacienda y necesario tras la supresión del pago de alcabalas en la villa. Según los oficiales con lo recaudado a través de la sisa habían contribuido a pagar la mitad del situado y cierto juro debido a Juanote de «Montaver» y al preboste de Fuenteberría, el salario del Corregidor - sin embargo éste había suspendido la sisa de 30.000 maravedís-, y de los oficiales e incluso parte de los gastos de la reparación del puente. Se señala que para la solicitud de ésta se tenía que convocar primeramente a todos los vecinos de «villa y tierra".

No menos interesante es la defensa que hacen de las tasas y precios fijados por el concejo sobre los productos y mercancías existentes en la villa para el consumo - paños, salarios de obreros y oficiales, etc.- El El concejo sostiene que para la resolución de dicho acuerdo se había determinado que estuviera presente el corregidor Juan de Ribera o su lugarteniente. Asimismo estuvieron presentes un procurador del común y los "oficios" que en tales casos se solían juntar. Sin embargo, a pesar de la estricta legalidad formal a que se había ajustado el acuerdo, parte del común se opuso a dichos precios, impidiendo de este modo que se llevaran a efecto dichos precios. Se acusa de ello a un personaje llamado Martino de Briasa, que junto con otras personas atemorizaba a quienes debían ejecutar estas medidas:

«...pero que como el dicho Martino e sus consortes toviesen hechas sus ligas y confederaciones y monipodios secretos non se avian guardado nin guardavan las dichas tasas de que avia rescresçido grand danno a la republica e que como los dichos ofiçiales sus partes estan atemorizados

25 Es posible que se refiera a las cartas que en 1477 emitieron los Reyes Católicos dando permiso para utilizar el sistema de sisas en la cantidad que el concejo y el Corregidor estimaran conveniente. Banús y AguiRre, J. L., El Archivo quemado..., pág. 75. 
de las condenaciones ynjustas que contra ellos se han fecho o no han osado executar nin prenderlos hasta saber la horden que nos mandaramos tener en ello para que las dichas tasas fuesen guardadas e las penas executadas e que... los dichos Martin y sus consortes hazian heran para escandalizar e alborotar la dicha villa e para que non se guardase las hordenanças ni oviese regimiento enella...».

Nuevamente se arguye negativamente contra este tipo de movimientos afirmando que se hacen para escandalizar y alborotar la villa de San Sebastián, impedir que se cumplan las ordenanzas y acabar con el regimiento. Pero además exigen que se condene a la parte contraria «en las penas contenidas en las dichas hordenanças commo açizanadas et alborotadores de la dicha villa». Esto, afirman hacerlo en nombre de las "duennas biudas menudas personas pobres e miserables» que estaban en el concejo.

Martino de Briasa, en nombre de la Comunidad y hombres buenos, resalta los agravios cometidos por los alcaldes, regidores y oficiales del concejo en perjuicio de la comunidad entre otras maneras pleiteando con su parte - a cuyos miembros califica de pobres - con el fin de que cesen estas últimas en su empeño por exigir justicia, al no poder seguir los pleitos por lo costosos que son. Exige que se cumplan las cartas ejecutorias dictadas hasta la fecha pagando los oficiales las penas correspondientes. Defiende el "movimiento popular» que se había generado en la vilia al afirmar que él mismo procuraba el bien público de San Sebastián.

Se reafirma en la discriminación de los oficiales concejiles a la hora de arrendar las carnicerías, pues se tenía más en cuenta el linaje y la parcialidad de los arrendatarios que la necesidad de sacar a subasta pública las mismas para entregarlas a quien más barato diera los productos y por tanto a quien ofreciera un mayor provecho al pueblo. Parece ser que en un primer momento se habían arrendado las carnicerías sin que salieran a subasta pública. Un tema de especial interés es el relacionado con el sistema electoral. En esta ocasión no se cuestiona el sistema de elección de los oficiales ordenado por la administración real, pues «les plasia que los dichos ofiçiales se elijiesen e nonbrasen segund e commo por nos avia seydo mandado e que dello non avian suplicado nin reclamado...». Ciertamente ya se habían dado cambios substanciales en relación con las ordenanzas de 1489.

Asimismo el procurador alegaba que su parte estaba de acuerdo con la nueva provisión dada en relación con la forma en que se habían de tomar las cuentas del concejo, pues hasta ahora los oficiales nombraban a cuatro personas «las que ellos querian para que encubriesen los robos 
e agravios que avian fecho en los bienes del dicho conçejo e para que fisyesen todo lo que ellos quisyesen...». Mientras que en aquélla dicho sistema había sido modificado. No obstante, solicitaba que se indicara el día en que se iniciaba este sistema de control y que se dieran los resultados antes de pasados 15 días. Asimismo estas cuatro personas habrían de recibir un salario «por su trabajo», cada uno de ellos 500 maravedís o lo que estipulase el concejo.

Por otro lado, negaba que su parte hubiera solicitado la desaparición de la sisa vieja o la "echada» con la que se pagaba el situado, a Juanote de "Monteabto" y al preboste de la villa de Fuenterrabía. La "comunidad» se había quejado tan solamente de las otras sisas e imposiciones nuevas que se pretendían recaudar mas allá de los gastos ya citados. En esta cuestión del pago de tributos fue todavía más preciso al denunciar que algunos sistemas fiscales gravaban a todas las familias por igual, cuando, sin embargo, la capacidad económica de los diversos núcleos familiares de la villa era bien diversa:

«...e que ya estava dicho e repetido muchas veces e justamente aviamos mandado proveer para que el ardite non se pagase de cada casa por que cosa ynjusta y ynica era que el rico e el pobre pechasen ygualmente...".

Está claro que la «comunidad» reivindica un sistema fiscal más justo que tenga en cuenta la distinta fortuna de los vecinos de la villa. Este es un aspecto que conviene destacar de manera particular, pues permite, sostener que este movimiento pueda ser considerado como popular, entendiendo esta acepción en el sentido más amplio del término, es decir, teniendo en cuenta los intereses de la mayoría de los vecinos de San Sebastián ${ }^{26}$.

En relación con las tasas y los precios fijados por el concejo sostiene que el vino y la sidra habian sido tasados a precios muy elevados. Si tenemos en cuenta que Martino ha sido erigido por la Comunidad en el representante de los intereses de la mayoria de la población, es evidente que ambos productos eran apreciados por la población. Se queja de que los jornales de los obreros - a los que denomina oficiales- y de otras

${ }^{26}$ Esta problemática preocupaba también a los habitantes de otras villas vascas. Véase al respecto GaRcía FERNÁNDEZ, E., "Fiscalidad y sociedad en la Pamplona medieval", Revista Sancho el Sabio. Vitoria 1992, Segunda Época, número 2, págs. 59-89 y del mismo autor «Finanzas y Fiscalidad de la villa de Lequeitio (1325-1516)", Anuario de Estudios Medievales, número 22 , 1992 (en prensa). 
gentes a las que califica como «hombres pobres» eran tan bajos que no se podrían mantener. Por ello defiende que se cumplan las sentencias anteriores que exigen a los oficiales que tengan en cuenta los precios existentes en las comarcas vecinas.

Asimismo está de acuerdo con la sentencia real en que se indican las formas en que se ha de prender a los que han cometido algún delito, la cárcel en que deben estar y las tasas que se han de pagar. Esta medida parece estar dirigida contra el preboste que tenía a los presos en su casa en lugar de hacerlo en la cárcel pública o cuando ésta se quemó, en la Torre de la iglesia de Santa María. En una línea parecida está la solicitud de que el bachiller Martín Ruiz no reciba por su salario más de 200 maravedís. Sentencia que fue apelada por éste ante el Corregidor.

La sentencia confirmó en líneas generales los dictámenes recogidos en otras cartas de fechas precedentes, si bien se introdujeron algunas puntualizaciones directamente relacionadas con algunos de los puntos en litigio. Estos fueron los siguientes:

- Las cuatro personas encargadas para tomar las cuentas a los oficiales del año anterior, hacer la tasa y los repartimientos habrían de ser nombradas por los oficiales del concejo, de acuerdo con las ordenanzas. Al "común" se le reserva el derecho a nombrar a otras personas para que estuvieran presentes en estas sesiones ${ }^{27}$. En esta ocasión se especifica la forma en que se han de elegir las personas que representarán a la Comunidad. Cada una de las parroquias separadamente y en presencia del Corregidor o de su lugarteniente nombrará a una persona «llana abonada» y vecino de San Sebastián que representará a la Comunidad en dichas coyunturas durante el año 1493.

Pero para el año 1494 cada uno de los dos representantes elegidos para este puesto en 1493 serían los encargados de nombrar en forma secreta a tres personas de su collación respectiva. A continuación una vez escritos sus nombres en un papel e introducidos los papeles en un cántaro se echaría a suertes. El primer papel que saliera de cada collación sería nombrado como diputado. Estos dos diputados serían los representantes de la comunidad, jurarían su cargo y su función sería la de «no consentir que en el se fagan fraudes ni yncubiertos algunas...».

27 A principios del siglo XVI se especifica que también estén presentes los oficiales nuevamente nombrados (AGSRGS 1518-VII-1). 
- Se permite que bajo el sistema recaudatorio de las sisas se ingresen hasta 30.000 maravedís con los que pagar el situado de la villa.

- Se perdona a los oficiales una tercera parte de la cuantía a que ascendía las penas y costas en que habían sido condenados.

- Se permite que el bachiller Martín Ruiz reciba cada día por su salario 230 maravedís, siempre que los dineros ingresados rebasen dicha cifra. En caso contrario el máximo que se le ha de pagar es de 200 maravedís.

Esta sentencia sentó las bases de las relaciones entre el común y el concejo de San Sebastián. La dialéctica establecida entre ambas partes continuará en años sucesivos. La comunidad irá recurriendo ante el Consejo Real todas aquellas actuaciones de los oficiales concejiles, consideradas por aquéllos contra derecho y procurará que las cuentas estén claras. Ya el 27 de septiembre de 1492 la universidad, en una carta dirigida al corregidor y al concejo de San Sebastián, exige al bachiller Martín Ruiz Elduayen que de cuenta de los 300 maravedís que le habían sido entregados por el concejo para seguir ciertos pleitos en la Corte ${ }^{28}$. Los pleitos entre el bachiller y el concejo y universidad continuaban en 28 de noviembre de 1493 y el 15 de diciembre de $1494^{29}$.

Pero uno de los aspectos que más siguió preocupando a la «comunidad» fue el sistema de elecciones. De hecho el 26 de noviembre de 1493 se dirigía al Consejo real el "pueblo y común" de la villa diciendo que antes los tenientes de corregidores nombraban los oficiales del concejo con el fin de evitar los "escándalos» que podrían producirse en las elecciones de los oficiales «a cabsa de las opiniones e parçialidades que en la dicha villa avian..." y exigen que el alcalde cumpla estos requisitos electorales. Los reyes ordenan al alcalde Zabaco, que esté presente en la elección, que se haga según las ordenanzas y que los nuevos oficiales no pertenezcan a ninguna parcialidad ${ }^{30}$.

Este tema, la forma de acceder a los cargos municipales y el conocimiento de las actividades socio-políticas de los miembros que serían nombrados, parece preocupar de manera especial a algunos sectores de la población de la villa, pues en 1494, Juan Bono, procurador del concejo, oficiales y hombres buenos solicita a los Reyes Católicos que actuén contra aquéllos que se reúnen banderizamente. Parece ser «que en la dicha

AGSRGS 27-|X-1492, fol. 53.

AGSRGS 15-XII-1494, fol. 354 .

AGSRGS Zaragoza, 26-XI-1493, fol. 73. 
villa en los dyas de las pascuas so color de jugar e aver plazer hazen juntas en casa de algunos vesinos e que los vesinos de la dicha villa so color de vandos e parentelas acuden a casas çiertas e conosçidas lo qual diz que es en deserviçio de dyos nuestro sennor en danno desa dicha villa...». La Comunidad parece quererse erigir, según algunas cartas documentales, en una de las más interesadas en el mantenimiento del «orden Público» ${ }^{31}$. De hecho en 1495, Martín de Larreaga, se dirigía a los RRCC, solicitando que ordenara al alcalde Tomás de Val de Olivas que ejecutara las sentencias dadas por su predecesor, Lorenzo de Montaud, con las que se pretendía castigar a los que habían provocado cierto alboroto ${ }^{32}$.

Todavía en este año la comunidad exigía ante el Consejo Real que el concejo divulgase entre los vecinos aquella carta real que prohibía que los carniceros pudieran ser regidores porque tasaban las carnes a precios más elevados y estando ellos en el poder las pesas solían ser fraudulentas porque no se cumplían por su desconocimiento general ${ }^{33}$. Pero aún en 1495 la comunidad, a través de su procurador, Martino de Larreaga, protestaba de que habían sido nombrados como oficiales de la villa algunos carniceros. En esta ocasión los oficiales se dirigieron a la Corte para defender el derecho de los carniceros a formar parte de los oficios concejiles, si bien la sentencia real no hizo sino confirmar las anteriores que favorecían a la comunidad ${ }^{34}$.

En estos años el alcalde era nombrado por la monarquía «por algunas cosas cunplideras a nuestro servicio e a la paz e sosyego desa dicha villa e a la administracion de la nuestra justyçia della...», como se afirma el 5 de diciembre de 1493, al confirmar en la alcaldía a Juan de Haro ${ }^{35}$. Las protestas por la subida de aranceles por parte del alcalde se dejaron sentir en 1493, así como en 1494 por el porcentaje que ingresaba él mismo proveniente de las ejecuciones del preboste ${ }^{36}$. En 1495 era alcalde el bachiller de Valdeolivas, asimismo nombrado por la administración Real. Pero en 1496 los Reyes Católicos ordenaban al Corregidor de Guipúzcoa, a solicitud de la villa de San Sebastián, que permitiera a la villa que tuvieran alcaldes ordinarios, de acuerdo con la costumbre antigua ${ }^{37}$. A

AGSRGS 16-V-1494, fol. 358.

2 AGSRGS Madrid, 19-V-1495, fol. 129.

3 AGSRGS Madrid, 15-II-1495, fol. 534.

4 AGSRGS Madrid, 29-IV-1495, fol. 312.

5 AGSRGS 5-XII-1493, fol. 5.

36 Archivo de la Real Chancillería de Valladolid. Reales Ejecutorias, leg. 70-38.

37 A G.S.R.G.S. 12-XII-1496, fols. 146 y 110 . San Sebastián alegó que "...la dicha villa estaba en toda paz e justicia e ninguna otra villa de la dicha provinçia non avia alcalde puesto por vos salvo los alcaldes hordinarios...". Asimismo Gonzalo de Salamanca, antiguo merino de Guipúzcoa, fue durante 6 meses alcalde de San Sebastián en tiempos del Corregidor Álvaro de 
comienzos del año 1497 ya había sido nombrados los dos nuevos alcaldes ordinarios de la villa, el mercader Vicente de Elduayen y Lorenzo de Montaot.

Este movimiento comunitario debió influir lo suficiente como para conseguir la modificación del viejo sistema electoral. En 1511 se confeccionaron unas ordenanzas en las que aparecian cambios notables en este sentido. Las elecciones se realizarían tras convocar a todos los vecinos residentes dentro del perímetro amurallado de San Sebastián. Todos los vecinos, cuya tasación fuera de un millar y medio, eran anotados en un «chartel» o papeleta e introducidos a continuación en una olla. Posteriormente un niño sacaría ocho «charteles» que serían los electores de cada año. Se ha de pensar que este cambio benefició a aquellos sectores de la población que hasta la fecha tenían prácticamente vedado su acceso al poder municipal y que lógicamente apoyaron normalmente las demandas de la Comunidad. Finalmente se había ensanchado la base participativa de la población en la política concejil ${ }^{38}$.

\section{CONCLUSIÓN}

La comunidad en el último cuarto del siglo xv se ha convertido en el árbitro de la política del regimiento de la villa de San Sebastián, merced a sus apelaciones ante el Consejo Real de Castilla. Se trata de un movimiento en su origen de carácter asambleario. El conjunto de la población se reúne en sus respectivas collaciones, ateniéndose a las dos circunscripciones parroquiales existentes, para nombrar a sus representantes —diputados y procuradores_. A su vez es un movimiento social de carácter reivindicativo que debe ser analizado en el marco de referencia de los conflictos sociales y políticos del siglo xv. Merece la pena destacar que disponía de unas mínimas estructuras institucionales para su funcionamiento, así como la pronta oligarquización real de sus representantes, al no ser la asamblea desde 1494 la que nombre a los diputados, sino los diputados del año anterior.

\footnotetext{
Porras. A éste se le exigen responsabilidades, tras dejar el cargo sin haberse realizado el pertinente juicio de residencia (AGSRGS, X-1497-218).

3s Pueden seguirse con precisión todos los detalles del sistema electoral de 1511 en el trabajo de AzconA, T. de, «El País Vasco durante la guerra de las Comunidades. Aspectos referentes a la historia de Guipúzcoa», Historia del Pueblo Vasco, 2. San Sebastián 1979, págs. 58-110. Del mismo autor es sugerente el libro titulado San Sebastián y la Provincia de Guipúzcoa durante la Guerra de las Comunidades (1520-1521). Estudio y documentos. San Sebastián 1974.
} 
Sin duda, estamos en presencia de una organización social que actúa como contrapeso de la presunta libertad de actuación de los oficiales del regimiento, sin que pretenda en absoluto subvertir o transformar el sistema de gobierno, según afirman ellos mismos en alguna ocasión. No obstante, en la práctica, consiguieron a medio plazo notables transformaciones en el mismo en favor de sectores cada vez más amplios de la población. La propia cohexión del movimiento favorecerá su consolidación y su autonomía de funcionamiento. La existencia en sí mismo de la "comunidad» que pone sobre la palestra la división de la población de San Sebastián en dos grupos, los que gobiernan y los gobernados.

La consecución de la «comunidad» del derecho de control de las finanzas municipales y la necesidad de su consentimiento en determinados asuntos que atañen al conjunto de la población - repartos fiscales, tasas de precios, salarios, etc.- si se quiere evitar el surgimiento de tensiones sociales, le otorga un relativo poder de control de la actividad de los oficiales concejiles nada desdeñable. Pero todas estas disputas evidencian el dinamismo existente en la villa de San Sebastián y la preocupación de sus habitantes por la "república», es decir, por todas las cosas que atañían a sus vecinos, además de por las características de su sistema electoral. 